\title{
"O Professor Universitário - Conferencista e Publicista - Perspectivas e Soluções”(*)e(**)
}

\author{
Fabio Maria de Mathias \\ Professor Adjunto do Departamento de Direito Civil \\ da Faculdade de Direito da Universidade de São Paulo
}

\begin{abstract}
SUMARIO: I - INTRODUGAO; II - O PROFESSOR UNIVERSITARIO COMO CONFERENCISTA; III - DIREITO MORAL DE AUTOR DO PROFESSOR UNIVERSITARIO COMO CONFERENCISTA E ESCRITOR: A) OBRAS ORAIS; B) OBRAS eSCRITAS; IV - DIREITo PATRIMoNIAL DE AUTOR DO PROFESSOR UNIVERSTTARIo COMO CONFERENCISTA E PUBLICISTA: A) OBRAS ORAIS; B) OBRAS ESCRITAS; V - LMITACOES AO DIREITO DE AUTOR NAS OBRAS ORAIS; VI LIMITACóS AO DIRETTO DE AUTOR NAS OBRAS ESCRITAS; VII - Perspectivas E solucofes.
\end{abstract}

\section{I - INTRODUÇÃO}

O tema da presente palestra não está sistematizado encontrando-se apenas acenos ao Direito de Autor do conferencista e do Professor-publicista tornando-se necessária a análise da atuação do Professor Universitário como conferencista e publicista num aspecto mais amplo, partindo das duas grandes prerrogativas, em que se desenvolve o Direito Moral de Autor e Direito Patrimonial de Autor.

O professor universitário como conferencista, como ministrador de aulas encontrará o conjunto de suas prerrogativas na regulação das obras orais a que se refere o artigo $6^{\circ}$, inciso $I I$ e em geral como autor de obra científica a proteção se encontra nos artigos $4^{\circ}$, inciso IV, 29 , 30 , entre outros da Lei 5.988/73.

$\mathrm{Na}$ categoria das obras abrangidas pelo artigo $6^{\circ}$, inciso II $-\ll \mathrm{e}$ outras obras da mesma natureza» - incluimos os cursos ministrados pelos professores universitários.

A proteção à atividade de conferencista ou professor se justifica, pois, como acentuava RENOUARD a palavra é um dos meios de fixa-

(*) Dedico este trabalho ao Professor Doutor CELSO LAFER, Mestre e Amigo.

(**) «O Professor Universitário - Conferencista e Publicista - Perspectivas e Solucões» - Palestra proferida aos 9 de maio de 1984 no Salão Nobre da Faculdade de Direito da Universidade de São Paulo, no Seminário «O ensino universitário e o Direito de Auton», patrocinado pelos, Faculdade de Direito da Universidade de São Paulo, IIDA-Instituto Interamericano de Direito de Autor e. Instituto Brasileiro da Propriedade Intelectual, no quadro das comemorações do cinquientenário da Universidade de săo Paulo. 
ção do pensamento sendo certo que a preparação de um discurso ou de uma conferência exige o mesmo trabalho que qualquer obra escrita. (1).

As obras orais muitas vezes, não são materializadas pela escrita, mas, devem, contudo, por ter a mesma natureza que as outras, gozar da mesma proteção. $\left({ }^{2}\right)$. As obras orais e, entre outras, os cursos são obras submetidas ao direito exclusivo do autor.

A palavra é um meio de exprimir o pensamento como a escrita (POUILLET).

Já o professor universitário como publicista encontrará proteção no Direito de Autor com relação às obras escritas e quanto à sua utilização através da reprodução ou mesmo da representação quando se tratar de videogramas ou na transmissão pela radiodifusão do conteúdo da obra.

\section{II - O PROFESSOR UNIVERSITARIO COMO CONFERENCISTA}

Lis conferências são protegidas enquadrando-se na categoria das obras orais que abrange, também, as leituras, os discursos, as aulas.

A oralidade da obra - sua comunicação ao público - nada mais é que a sua representação, e, pois, lídimo exercício de uma prerrogativa autoral, já que o improviso é a produção no momento de sua criação e gera direitos autorais plenos. ${ }^{(3)}$.

Ao falarmos em conferências referimo-nos à atuação do professor universitário em atividades no âmbito da Universidade e em atividades externas junto à coletividade, o que se revela de modo esporádico.

Mas existe a proteção às obras intelectuais que se concretizam na ministração de aulas, atividade caracterizada pela constância e continuidade.

As obras orais, sejam discursos ou improvisações, são protegidas em benefício de seus autores, estando proibida sua difusão através da reprodução (edição de livros ou, discos, gravações) ou execução pública (radiodifusão direta ou de discos) na medida em que exceda os objetivos do orador. $\left(^{4}\right)$.

ETTORE VALERIO E ZARA ALGARDI ensinam que as obras orais se enquadram na categoria das obras literárias porque as aulas dos professores, os discursos, os sermões não poderiam ser catalogados

(1) PAUL OLAGNIER - «Le Droit d'Auteur» tome premier, Paris, Librairie Générale de Droit et de Jurisprudence, 1934, pág. 27.

(2) NICOLA STOLFI - «La Proprieta Intellectuale», volume primo, Torino, Unione Tipografico Editrice Torinese, 1915, pág. 410.

(3) EDUARDO VIFIRA MANSO - «Direito Autoral», São Paulo, José Bushatsky Editor, 1980, pág. 111.

(4) ISIDRO SATANOVSKY - «Derecho Intelectual», Buenos Aires Editora Argentina, 1954, pág. 173. 
diferentemente, pois nelas quase sempre há prevalência de uma manifestação literária.

A lei $n^{9} 5.988 / 73$ aceita a distinção entre obras literárias e científicas e no estudo que ora iniciamos trataremos de obras orais científicas.

Ressaltam VALERIO E ALGARDI que as obras orais devem ser consideradas por si mesmas, e não como obras cuja forma é apenas provisória, destinando-se a serem substituidas pela forma escrita. Enquanto, as vezes, a forma oral é efetivamente provisória, outras vezes, ao invés, tem caráter definitivo alcançando sua finalidade com a forma oral ainda que nunca venham a ser publicadas quer pela impressão ou sequer transcritas. Portanto a obra oral deve ser considerada como um modo particular de publicação da obra intelectual. ( $\left.{ }^{5}\right)$.

Mas é necessário salientar que as manifestações orais para serem tuteladas devem preencher sempre os requisitos de obra intelectual, ou seja revelar aquele minimo de atividade intelectual original e criativa. $\left(^{6}\right)$.

Para ALAIN LE TARNEC o autor de uma obra oral deve comprovar um espírito criador semelhante ao de uma obra escrita; a originalidade pode se manifestar na composição ou na expressão de uma obra oral como na de uma obra escrita. (7).

Lembra HENRI DESBOIS que isto é válido tanto para as improvisações como para as obras redigidas com antecipação e pronunciadas tal como são escritas, o mesmo sucedendo com os cursos ministrados pelos professores.

As conferências são protegidas quer seja seu ator um simples particular quer político. Nesta última hipótese as limitações ao seu direito de autor serão mais extensas. $\left.{ }^{8}\right)$.

Como vimos na introdução, ao tratarmos do professor universitário como conferencista, incluímos a ministração de cursos aos seus alunos, pois, são frutos de uma pesquisa pessoal, destinados a uma comunicação oral e não podem ser reproduzidos sem a autorização de seu autor, pois, o professor está obrigado ao ensino apenas para o seu público. ${ }^{(9)}$.

Mas há sistemas jurídicos em que as exigências para a atribuição de proteção são maiores. O direito americano para a proteção de

(5) ETTOR日 VALERIO @ ZARA ALGARDI - «Il Diritto d'Autore», Milano, Dott. A. Giuffrè Editore, 1943, pag. 26

(6) ETTORE VALERIO e ZARA ALGARDI - ob. cit., pág. 26.

(7) ALALN LE TARNEC - «Manuel de la Propriété Littéraire et Artistique», Paris, Librairle Dalloz, 1966, pág. 202.

(8) CLAUDA COLOMBET - «Propreté Littéraire of Artistique», Paris, Dalloz, 1966, págs. 47 e 48.

(9) CLAUDE COLOMBET - ob. eit., pag. 49. 
uma conferência exigia que ela se corporificasse num escrito, pois, a proteção pelo Direito de Autor só era outorgada às conferências, sermões, alocuções preparados antes de serem pronunciados, No mesmo sentido o artigo $3^{\circ}$ da Convenção de Washington. Orientação idêntica foi adotada no direito inglês $\left({ }^{10}\right)$.

\section{III - DIREITO MORAL DE AUTOR DO PROFESSOR UNIVERSI- TÁRIO COMO CONFERENCISTA E ESCRITOR}

Neste capítulo há de ser ressaltar um enfoque especial motivado pelas características peculiares da obra oral.

\section{A) OBRAS ORAIS}

O professor universitário que ministra uma aula, que profere uma conferência está investido do poder de autorizar ou não a reprodução de sua obra oral, pois, investido nesse poder de autorizar ou não resguardará o seu direito de corrigir as imperfeições na forma e substância que ocorrem na obra oral.

Esta prerrogativa concedida ao autor da obra oral que sua vontade seja violada quando não desejar que ela se submeta a uma publicidade mais ampla da que objetivara. (11).

O fato de o conferencista, do professor se dirigir a um certo público, comunicando-lhe sua obra não implica no entendimento de que a queira colocar em contato com todo público, dai se justificar a necessidade de autorização para a reprodução. ${ }^{(12)}$.

E com base no direito moral de autor que o professor universitário pode se opor à divulgação de sua exposição além do círculo das aulas pois julgando seu curso imperfeito, deseja melhorá-lo, atualizá-lo em condições que o satisfaçam.

Todos sabemos da diferença entre a exposição oral - onde as qualidades pedagógicas são primordiais - e a obra escrita. Daí a necessidade de se verificar as fontes de informações, completar as referências a autores, legislação etc., enriquecer e aprofundar uma argumentação ou redigir de forma mais feliz. (13).

MICHĖLE SALCZER-SANCHES ressalta a importância da liberdade de que gozam os professores, tanto para com eles como em relação aos próprios alunos. O controle pelo professor da publicação de seu curso permite se evitar a desnaturação de seus fins o que pode-

(10) ANDRE FRANCON - «La propriété littéraire et artistique en Grande Bretagne et aux Etats Unis», Paris, Librairie Arthur Rousseau, 1955, pág. 30.

(11) NICOLA STOLFI - ob. cit., pág. 410.

(12) CLAUDE COLOMBET - ob. cit., págs. 47 e 48.

(13) GeRARD LYON-CAEN - «La publication des cours des professeurs d'Universitế», em Revue Internationale de Droit d'Auteur, volụme LII, págs. 159 e 161. 
ria surgir com a simples transcrição do mesmo, por mais fiel que ela seja. Isto porque a forma falada permite variações e retoques e efeitos oratórios que fixados por escrito podem desagradar seu autor. A necessária autorização pelo professor para a divulgação de sua obra - por reprodução ou representação - configura garantia da qualidade do ensino. $\left.{ }^{14}\right)$.

Em verdade o direito moral de autor do conferencista, do professor universitário se calça numa tríplice fundamentação constante dos incisos III, IV e V do artigo 25 da Lei $\mathrm{n}^{\circ} 5.988$.

\section{B) OBRAS ESCRITAS}

Com relação ao direito moral de autor do professor universitário como autor de obra escrita está ele protegido pelos vários institutos de que se compõe aquele direito nada havendo de especial a ser ressaltado, não se tendo encontrado nenhum subsídio particular.

Um exemplo pode ser dado da atividade intelectual do professor universitário sem que se refira propriamente à publicação de obra escrita ou aproveitamento de obra oral. É o direito à paternidade de que desfruta o professor universitário quando organiza e dirige uma revista e se configura sua co-autoria.

Outro exemplo encontramos no direito à paternidade quando o professor universitário elabora sumários, índices - remissivos de uma coletânea de artigos, de diplomas legais impondo-se que tal autoria deve ser reconhecida em respeito ao seu direito moral de autor.

É necessário, também, falar do professor universitário como Diretor de Revista: como o direito positivo considera quem organiza e dirige a revista como autor de obra coletiva, está ele investindo do direito de reivindicar a paternidade da obra coletiva e de ser opor, no exercício do direito moral de autor, a qualquer deformação, mutilação ou qualquer modificação que possa atentar à sua honra ou reputação.

\section{DIREITO PATRIMONIAL DE AUTOR DO PROFESSOR UNI- VERSITARIO COMO CONFERENCISTA E PUBLICISTA}

\section{A) OBRAS ORAIS}

O autor de obra oral - conferência, aula, curso - está investido da faculdade de publicá-la através da transcrição de improvisações, de leituras e ensinamentos orais, ainda que efetuados em público, o que poderá ser efetuado através da estenografia, da gravação, da fixação material em video-tape, etc.

(14) MICHELE SALCZER-SANCHEZ - «Le droit d'auteur et les necessités de l'enseignement», em Revue Internationale du Droit d'Auteur, volume 110, pág. 143. 
O Direito de Autor reaparece com suas prerrogativas e o autorconferencista encontra, como qualquer outro autor, os meios de defender sua obra contra todas as iniciativas tomadas por terceiros ( ${ }^{15}$ ).

Portanto apenas os autores - como titulares de direitos - podem autorizar sua publicação. Quer a criação seja escrita quer oral somente seu autor poderá dela dispor, e a ele, tão somente, cabe a escolha do processo de reprodução e se a reprodução ou representação se fará a titulo gratuito ou oneroso.

Mas as conferências não podem ser transcritas em jornais e diários sem a autorização do seu autor vez que a limitação constante do artigo 49 , inciso I, letra «c» da Lei número 5.988 refere-se a reprodução «em diários ou periódicos, de discursos pronunciados em reuniões públicas de qualquer natureza» e devemos distinguir as conferências dos discursos admitindo-se apenas notícias, resumos e quando for o caso da transcrição integral, daquelas quando proferidas em reuniões públicas. (16).

Há distinção entre a conferência, a aula de um professor universitário e as limitações decorrentes do direito à informação a que se subordinam os discursos proferidos em reuniōes públicas por certas pessoas.

O professor universitário deverá autorizar a reprodução de sua conferência, de seu curso sem o que haverá violação ao seu direito patrimonial de autor.

Também se submete a mesma regra a transmissão da aula por radiodifusão, fixação material em suporte magnético ou mecânico, etc. (17).

Isso se justifica na defesa do direito de utilização do professor universitário como prerrogativa de seu direito pecuniário de autor.

Passemos à análise da repercussão ocasionada no mundo do direito autoral pelos cursos ministrados pelos professores universitários.

Os cursos ministrados pelos professores universitários são tutelados?

Eles o são sofrendo apenas a limitação prevista no artigo 49 , n IV da lei $n^{\circ} 5.988$.

Houve intensa polêmica a respeito.

Alegou-se que os cursos não deveriam ser considerados obra protegida por causa: a) do uso ilimitado que os ouvintes têm sobre as aulas de seus professores; b) da renumeração que percebem do Estado ou de instituições privadas para ministrarem os cursos.

(15) ALAIN LE TARNEC - obra citada, pág. 203.

(16) JOSE DE OLIVEIRA ASCENSKO - «Direito Autoral», Rio, Forense, 1980, pág. 257 - nota 8 - onde diz «Por outro lado, sugerem Mouchet - Radaelli, Derechos, que se distingam discursos e conferências, e se exclua a reproduçáo total destas».

(17) GERAD LYON-CAEN - ob. cit., pág. 159. 
NICOLA STOLFI respondia a estas objeçōes com os seguintes argumentos: a) se é verdade que os alunos podem utilizar dos princípios ensinados pelos mestres não poderão, contudo, especular com base na criação dos professores; b) os professores assumem o compromisso tão somente de ministrar os cursos e não o de publicar suas aulas ou conferências. Isto porque os efeitos dos dois atos são diferentes vez que a aula permanece entre os alunos que a assistem enquanto que sua publicação a divulga no mundo dos estudiosos, proporcionando as idéias manifestadas um caráter mais firme e estável. ${ }^{(18)}$.

Por outro lado a renúncia do professor ao direito de autor sobre suas aulas não beneficiaria o Estado ou a entidade particular da qual ele é professor mas a qualquer especulador que queira aproveitar-se. $\left({ }^{19}\right)$.

Mas a tutelabilidade das aulas, conferências do professor universitário se justifica, pois, o professor no exercício da atividade docente incorre em inexatidões quanto à forma e ao conteúdo que certamente eliminaria se fosse o caso de proceder à sua publicação. Mas, já vimos, esta é uma manifestação do direito moral de autor.

A salvaguarda da precisão do pensamento do professor justifica que não se possa atribuir a qualquer pessoa a faculdade de publicar as aulas mesmo se em forma de apostilas, portanto, para o uso dos discentes. $\left.{ }^{(20}\right)$.

A jurisprudência francesa a partir de 1828 fixou a tutelabilidade dos cursos dos professores (21) e a evolução jurisprudencial da matéria na França é relatada pelo Professor GÉRARD LYON-CAEN em seu artigo já citado. Decisão do Tribunal de Roma, datada de 15 de abril de 1915, concebeu a proteção nos seguintes termos: «l' autore che rende pubbliche le concezioni del suo ingegno non può reclamare la padronanza se non per la forma esteriore e sensibile con cui le ha estrinsecate, e questa sola può essere suscettiva di tutela giudidica». $\left({ }^{22}\right)$.

$\mathrm{O}$ artigo $3^{\circ}$ da lei prussiana de 11 de junho de 1837 qualificava como contrafação a impressão, efetuada sem a devida autorização do autor, dos sermões ou cursos ministrados oralmente ou escritos por um dos ouvintes, quer a publicação tenha ocorrido sob o verdadeiro nome do autor quer a tenha o contrafator feito em seu nome.

A lei inglesa de 9 de setembro de 1935 especialmente dedicada às obras orais dispunha: «Quem, por meio da estenografia, ou por qualquer outra fixação, tenha obtido ou feito uma cópia de obras emitidas oralmente e as tenha publicado ou feito publicar... sem o consentimento do autor, ou de seu titular, e quem tenha com conhecimento vendido,

(18) NICOLA STOLFI - ob. cit., pag. 415.

(19) NICOLA STOLFI - ob. cit., pág. 415.

(20) NICOLA STOLFI - ob. cit., pág. 416.

(21) NICOLA STOLFT - ob. cit., pag. 415, nota 2.

(22) NICOLA STOLFI - ob. cit., pág. 415. 
publicado, comercializado, ou feito comercializar esta obra, será passível de confisco dos exemplares impressos e de uma multa de $\mathrm{x}$ para cada folha encontrada em seu poder, impressa litografada ou copiada».

Alguns processos em que se discutem os direitos do professor sobre seu curso geraram jurisprudência norte-americana examinada por BARBARA RINGER em artigo denominado «Judicial developments in United States Copy right law (1968-1968)». $\left.{ }^{23}\right)$.

A proteção outorgada aos cursos dos professores universitários é matéria insuscetível de discussão.

$\mathrm{O}$ argumento de que o professor universitário estaria obrigado à publicação de seu curso em decorrência de sua ligação para com um estabelecimento de ensino quer publico quer privado é unanimemente refutado. Nada impede, contudo, que contratualmente o professor universitário assuma uma tal obrigação.

\section{B) OBRAS ESCRITAS}

Os professores universitários por escreverem obras cientificas raramente delas tiram um considerável proveito econômico.

Mas a prerrogativa do autor de só ele autorizar a divulgação de resumos de seus cursos, de apostilas calçadas nos mesmos, etc. liga-se ao seu direito patrimonial de autor que poderá ser prejudicado quando desejar publicar seu manual ou tratado sobre a matéria que ele domina e ensina.

Tal cautela é importante até para possibilitar a publicação de sua obra, pois, o editor sabendo que não haverá interesse para a aquisição pelos alunos desinteressar-se-á da publicação obstando a fixação material dos seus conhecimentos do professor o que é indispensável para o professor científico. ${ }^{(24)}$.

Daí a necessidade de se combater a publicação de apostilas por ferir o direito patrimonial de autor quer conseguidas através da fixação material das aulas quer quando apenas extratos, excertos, resumos sejam objeto de publicação, partindo de referidos meios de fixação ou mesmo quando resumos de textos publicados são reproduzidos e distribuídos entre os alunos.

Muitas vezes pensam mascarar a ilicitude com o uso da expressão «sem responsabilidade da ilustre cátedra» na folha de rosto da publicação.

$\mathrm{Na}$ análise do direito patrimonial de autor do professor universitário como publicista apontamos um aspecto em que são freqüentes as violaçōes.

(23) Em Revue Internationale du Droit d'Auteur, volume LXVIr, janeiro de 1971.

(2A) GERARD LYON-CAEN - ob. cit., pág. 161. 
Não nos cabe um desenvolvimento da matéria, pois, toda a regulação do direito patrimonial de autor, assunto suficientemente consolidado e de caráter irrefutável, se aplica à matéria.

Não poderíamos contudo deixar de acenar para um aspecto prático de muito relevo e que se constitui em constante falta de respeito para com os seus autores - os articulistas - professores universitários.

Artigos em revistas - $\mathrm{O}$ professor universitário que fornece um artigo para ser publicado em revista, portanto, em obra coletiva mantém o direito de reproduzí-lo em «estratti separati» como obra independente e em volume onde também são aproveitados outros trabalhos seus.

Contudo está obrigado a indicar a obra coletiva em que o artigo foi publicado, com indicação do volume, data da publicação, numeração das páginas, etc.

Por outro lado o professor universitário mantém o direito, salvo pacto em contrário, de reproduzir em outras revistas ou jornais os artigos anteriormente publicados em revistas ou jornais respeitado $o$ que se indicou no parágrafo anterior. ${ }^{25}$ ).

$O$ desrespeito ao direito patrimonial de autor se configura com a habitual, pelo menos entre nós, falta de remuneração quando da publicação de artigos em revistas cabendo ao autor o consolo de ter tido cportunidade de comunicar sua obra com o público.

É bem verdade que com relação a verbetes elaborados para publicação em Enciclopédias Jurídicas tem ocorrido remuneração o que já significa uma reação ao mau hábito vigorante.

O professor universitário que enviar artigo para publicação em uma revista sem que tenha sido solicitado não poderá reclamar do editor ou diretor da revista a devolução dos originais ou que o conserve em seus arquivos, pois não existe a obrigação de conservar ou restituir os manuscritos, os originais dos artigos não reproduzidos por não terem sido solicitados. $\left({ }^{26}\right)$.

Tratando-se de artigo para revista ou jornal, se é enviado por pessoa estranha à redação e sem que algo haja sido pactuado a respeito, o autor retoma o direito de dispor livremente quando não tenha recebido notícia da aceitação. $\left.{ }^{27}\right)$.

Configurar-se-á, então, uma dupla violação: ao direito moral de autor, porque o professor poderá não desejar nova publicação daquele trabalho por várias razões, como não estar satisfeito com aquela obra

(25) GIUSEPPE PADELLARO - «n Diritto d'Autore - la Disciplina Giuridica degl Strumenti di Communicazione Sociale», Milano, Casa Fditrice Dr. Francesco Vallardi Societa Editrice Libraria, 1972, página 33..

(26) GIUSEPPE PADELLARO - ob. cit., pag. 33.

(27) GIUSEPPE PADELLARO - ob. cit., pág. 32. 
intelectual, porque ela perdeu atualidade ou porque ela deva ser retocada para ser atualizada, etc. A infração ao direito patrimonial do autor se caracterizará com a publicação sem sua autorização importando em desrespeito à sua prerrogativa de ser remunerado pela reprodução de seu trabalho.

\section{V - LIMITAÇões AO DIREITO DE AUTOR NAS OBRAS ORAIS}

Um discurso, uma conferência a despeito de serem protegidos e, portanto, não poderem ser publicados sem autorização do titular de direito, sofrem a limitação consubstanciada no direito de citação.

Os alunos ou ouvintes poderão anotar o pensamento, a idéia externada pelo professor mas não poderão reproduzí-la por qualquer processo que seja, anda que, se destinado a uma clientela restrita. (28).

Com relação aos cursos, o artigo 49 , inciso IV da Lei n' 5.988 , cria uma limitação aceita nas legislações no sentido de que «o apanhado de lições em estabelecimentos de ensino por aqueles a quem elas se dirigem, vedada, porém, sua publicação, integral ou parcial, sem autorização expressa de quem as ministrou «não se configurarem como violações ao direito de autor».

Outra exceção ao direito exclusivo dos autores no que diz respeito à obra oral encontramos nas obras de professores universitários que tenham sido objeto de fixação audiovisuais originariamente destinadas ao ensino e que poderão ser submetidas a limitações ao direito do autor, no que se refere aos países em vias de desenvolvimento, na forma de licenças legais ou obrigatórias de tradução e de reprodução de obras necessárias para o ensino quando não for possivel obter licença negociada.

ALAIN LE TARNEC pondera que o ouvinte, o aluno, tem o direito e o dever de fazer anotaçōes da aula, podendo, se o desejar, estenografar todo o curso ministrado. ${ }^{29}$ ).

Mas a obra oral está, em certos casos, muito ligada à atualidade e nesta eventualidade a informação do público exigirá que ela possa ser livremente reproduzida. A proteção de algumas categorias de obras orais é, por vezes, suprimida ou suspensa de modo temporário, em razão da necessidade de informação do público, por ser uma das hipóteses em que o direito de autor deve ceder diante do interesse da coletividade. $\left({ }^{30}\right)$.

Portanto as disposições de Direito de Autor, quer a nivel nacional quer a nível convencional, não sacrifiquem aos direitos do público quando estes se apresentam como legítimos.

(28) PIERRE POIRIER - «Le Droit d'Anteur», Bruxelles, Maison Ferdinand Larcler, sem data, págs. 136 e 137.

(29) ALAIN LE TARNEC - ob. dit., pág. 205.

(30) CLAUDE COLOMBHT - ob. cit., pags. 47,48 e 49. 
Mas é proibida a utilização coletiva. Na lição de HENRI DESBOIS a exceção se circunscreve ao direito do estudante de efetuar anotações mas «seu direito pára aí», constituindo abuso a distribuição de suas notas. ${ }^{\left({ }^{1}\right)}$. Tratando-se de uma exceção a uma regra de princípio essas regras devem ser interpretadas estritamente e, portanto, o legislador desejou apenas favorecer o usuário individualmente.

O professor se dirige ao público que assiste às aulas, o ensinamento destina-se aos estudantes presentes que as ouvem, estes constituem os usuários e seu direito se localiza tão somente em ouvir e tomar notas. $\left({ }^{32}\right)$.

A difusão do texto do curso às pessoas não presentes à sua ministração violaria esta regra absoluta de que ao autor é proporcionado o direito de explorar sua obra ou de autorizá-la o faça terceiro, e desconheceria a vontade do professor de circunscrever seu ensino aos alunos ouvintes.

Não há que se distinguir - sob o ponto de vista do Direito de Autor - em função do número de público admitido ao curso (seminário com público limitado, curso franqueado ao público). ${ }^{\left({ }^{33}\right)}$.

Interessante que no direito americano só se admite um resumo na imprensa quando se tratar de alocução pronunciada perante o público quando não houver aviso, no local, proibindo tal utilização. ${ }^{(34)}$.

As leis mais recentes tendem a aumentar as limitações ao direito de autor.

A lei peruana no seu artigo 67 não condiciona a utilização para fins de notícia, mas, autoriza que os discursos, as conferências possam publicar-se ou com fins informativos ou para dar conhecimento à coletividade, o que dá a entender que toda a conferência poderá ser reproduzida.

O artigo 40 da Lei de Direito de Autor da Colombia, $\mathrm{n}^{\circ} 23$, de 28 de janeiro de 1982, estatui que o texto das conferências ou dos cursos pronunciados nos estabelecimentos de ensino superior, secundário ou primário pode ser anotado e recolhido livremente pelos alunos aos quais se destina, mas sua publicação ou reprodução integral ou parcial é proibida sem autorização escrita de quem a pronunciou.

Mas esta lei, no seu artigo 35, permite que as conferências, alocuções, sermões e outras da mesma natureza pronunciadas em público possam ser publicadas na imprensa periódica ou radiodifundidas sem autorização sob a forma de notícias de atualidade desde que o autor não tenha reservado expressamente sua titularidade.

(31) ANDRE FRANCON - ob. cit., pág. 151.

(32) HENRI DESBOIS - «Le Droit d'Auteur en France», Paris, Dalloz, no 42, 1966, págs. $54 \odot 55$.

(33) GERARD LYON-CAEN - ob, cit., pág. 157.

(34) GRRARD LYON-CAEN - ob. cit., pág. 159. 
A nivel de Direito Convencional os discursos, as conferências estão submetidos à limitação que permite sejam feitos resumos, extratos quando isto se impuser por se tratar de assunto de atualidade.

HENRI DESBOIS, ANDRÉ FRANCCON e ANDRÉ KEREVER consideram que a noção de atualidade deve ser entendida num sentido mais extenso: a utilização deve ser justificada pelo escopo de informação a alcançar, quer dizer que o caráter de atualidade não se deve referir ao assunto tratado na conferência, alocução, etc. mas aplicar-se-á própria utilização com o fim de informar o público. Pouco importa que o assunto tratado mergulhe nos séculos passados: é o interesse que a difusão do exposto apresenta que determina sua atualidade e corresponde à condição imposta na alínea 2, in fine, do artigo 10 da Convenção de Berna, a saber «le but d' information à atteindre». ( $\left.{ }^{35}\right)$.

Nesta limitação, tendo em conta a finalidade da imprensa e atendendo à satisfação da informação pública, incluem-se os discursos, as conferências enfim toda comunicação feita oralmente a um público, restrito (caso de conferênciais ou não). $\left({ }^{36}\right)$.

\section{VI - LIMITAGões AO DIREITO DE AUTOR NAS OBRAS ESCRITAS}

A despeito da regra de que o titular da obra intelectual está investido do direito exclusivo de utilizá-la ou autorizar sua utilização encontramos a limitação constante do artigo 49, inciso II da Lei $n^{\circ} 5.988$ que interessa ao professor universitário como autor.

Por tal dispositivo legal, não constitui ofensa ao direito do autor a reprodução, em um só exemplar, de qualquer obra, contanto que não se destine à utilização com intuito de lucro.

Em seguida examinaremos o perigo de uma interpretação litera] desta regra no que concerne à utilização de meios de reprodução da obra como pela reprografia, pois, poderá configurar utilização coletiva na expressão de HENRI DESBOIS.

Outrossim constitui limitação ao direito de autor do professor universitário a prerrogativa reconhecida, pelo artigo 49 , inciso III da Lei $\mathrm{n}^{\circ} 5.988 / 73$, a terceiro quanto ao exercício do direito de citação permitindo a transcrição em livros, jornais ou revistas, de passagens de qualquer obra, para fins de estudo, critica ou polêmica.

Também concerne ao professor universitário a limitação ao direito de autor prevista no artigo 49, I letra a da Lei $n^{0}$ 5.988/73 não consi derando ofensa a «reprodução de trechos de obras já publicadas, ou

(35) HENRI DESBOIS, ANDRE FRANCON A ANDRF KEREVER - «Les conventions internationales du droit d'auteur et des droits voisins», Paris, Dalloz, 1976, pág. 195.

(36) EDUARDO VIEIRA MANSO - ob. cit., pág. 111. 
ainda que integral, de pequenas composições alheias no contexto de obra maior, desde que esta apresente caráter científico, didático ou religioso, e haja a indicação da origem e do nome do autor.

Algumas outras exceções à regra da exclusividade encontramos em disposições legais limitadoras do exercício dos direitos autorais quando se tratar de obras utilizadas com fins pedagógicos.

\section{Sistema americano -}

A lei de Direito de Autor dos Estados Unidos, no seu artigo 107, permite que a reprodução de uma obra intelectual não se submeta ao direito exclusivo quando se tratar de uso legal por se destinar aos fins de ensino inclusive a duplicação para uso em aula que pode consistir em uso legal.

Referida norma legal é aplicada relativamente à reprodução com fins educacionais nos estabelecimentos de ensino sem fins lucrativos para o que se determinou estarem autorizadas apenas reproduções, em número limitado, de obras curtas ou extratos de obras longas, quando o professor não teve tempo suficiente para obtenção de autorização, sem que nenhuma contraprestação esteja prevista.

Certas reproduções em exemplar único efetuados nas bibliotecas estão fora da abrangência do direito de reprodução (artigo 108 da lei americana). Com base nesse dispositivo legal os alunos podem se utilizar da reprografia.

\section{Sistema sueco -}

A lei de 1960, modificada em 1973, comporta exceções ao exercício do direito de autor especificamente destinadas ao ensino. $\mathrm{O}$ artigo 16 autoriza a reprodução de obras curtas ou extratos de obras longas em coletâneas com caráter pedagógico. Exige contudo que as obras reproduzidas tenham sido publicadas há cinco anos e que não se destinem ao ensino. Tal reprodução é efetuada mediante o pagamento de remuneração. ${ }^{(37) \text {. }}$

\section{Sistema alemão.}

A lei da República Federal Alemã contém disposições semelhantes às da lei sueca. O artigo 46 está próximo do artigo 16 da lei sueca: diz respeito às reproduções de obras em coletâneas com caráter didático. Há diferenças quanto aos pormenores em relação à lei sueca: pelo artigo 46, alínea $5^{\mathrm{a}}$. o autor da obra reproduzida deve ser informado a respeito e poderá se opor à reprodução desde que tenha previamente revogado um direito ao uso que lhe cabia consentir.

(37) MICHELE SALCZER-SANCHEZ - ob. cit., pág 155. 
Discutivel inovação se encontra no artigo 62 , alínea $4^{\mathrm{a}}$ ao indicar que se a obra for reproduzida com fundamento no artigo 46 é possivel introduzir algumas modificações necessárias à utilização para fins pedagógicos.

O artigo 47 da lei objetiva a reprodução sonora de obras compreendidas em programas de emissões escolares.

As leis suecas e alemã são modelos de legislações que têm em conta as necessidades particulares do ensino, ainda que, limitando o mais possível o risco de prejudicar os autores. Elas apresentam soluções que se situam a meio caminho entre a lei francesa que não dispõe de nenhuma regra específica para o ensino. $\left.{ }^{38}\right)$.

A Lei de Barbados, de 22-01-1982 no artigo 24 número 1, letra c) estatui limitação ao direito de autor autorizando a utilização da obra a título de ilustração para o ensino através de publicações, emissões pela radiodifusão ou gravações ou, na medida justificada pelo fim a alcançar, comunicar a obra com escopo de ensino através de emissão de radiodifusão destinada às escolas e universidades, à formação profissional ou à educação pública, desde que a obra se tenha tornado licitamente de conhecimento público. O número 4 do mesmo artigo 24 falando de limitação contida na sua letra $\mathbf{g}$ ) da alínea $1^{\text {a }}$ dispõe não se aplicar senão na medida em que a reprodução está descrita e que o número de exemplares fixados não excedam os limites do que é necessário. ${ }^{39}$ ).

As obras dos professores universitários poderão ser objeto de limitações ao direito de autor, no que se refere aos países em vias de desenvolvimento, na forma de licenças obrigatórias ou legais de tradução e de reprodução de obras de que se necessitem para o ensino quando não for possivel obter licença negociada.

A Convenção Universal de Direito de Autor regula a matéria no artigo $\mathrm{V}$ bis à $\mathrm{V}$ quater enquanto que no âmbito da Convenção de Berna consta a regra do artigo III do Anexo.

A Lei-tipo de Tunis, de 1976, também dispõe sobre a utilização de obras com fins pedagógicos.

Com o passar do tempo, novas técnicas de comunicação vão criando limitações ao direito de autor como veremos no capitulo dedicado às perspectivas e soluções.

\section{VII - PERspectivas E solugões}

O Professor Universitário raramente consegue auferir vantagens econômicas de porte, com a reprodução ou representação de suas obras

(38) MICHELE SALCZER-SANCHEZ - ob. cit., pág. 157.

(39) Revue Internationale de Droit d'Auteur, volume 117. 
intelectuais. A exceção se apresenta na eventualidade de publicação de textos em forma de manual ou mesmo em forma de tratados.

Um aspecto, entre nós, lamentável é o hábito de não se remunerar pela utilização de artigos para revistas, muitas vezes apenas fornecendo ao autor exemplares do artigo em forma de separata.

A título de homenagem o autor do artigo receberá um exemplar do volume em que seu trabalho foi publicado.

Será oportuno lançar-se um movimento de esclarecimento no sentido de ser valorizado o labor do professor universitário através de pagamento de uma remuneração, ainda que módica, ao seu autor.

Certamente será alegado que essas publicações se ressentem de dificuldades financeiras, que a remuneração é impraticável quando não se afirmará que o professor universitário deve ser grato por ter um veículo por onde se comunicar com o público!

Paralelamente reinvindicar-se o hábito de fornecimento de separatas, eis algo que se impõe.

Mas novos meios de reprodução da obra intelectual têm se configurado como violação ao direito de reprodução do autor, tornando-se difícil o respeito a essa prerrogativa face o argumento da necessidade de acesso às fontes de informação. Enfim o desenvolvimento de técnicas modernas de reprodução de obras gerou novas dificuldades.

Um desses meios é a reprografia que tanto pode ter seu uso enquadrado nas limitações do direito de autor, nos termos do artigo 49, inciso II da Lei $n^{\circ} 5.988$, como quando é utilizado com base em tal inciso mas com evidente violação do direito de autor por causa da interpretação extensiva dada à lei de regência.

Em verdade uma forma de utilização é efetivada por um aluno para seu uso pessoal e outra quando dezenas ou centenas de alunos por orientação de seu professor reproduzem textos de autores científicos para seu uso pessoal dispensando deste modo a aquisição de livros em prejuízo do autor e do editor que nada recebeu por esta forma de utilização.

O professor universitário não deverá ser prejudicado em seu direito patrimonial de autor pela necessidade que os alunos têm de acesso aos textos.

Mas a necessária democratização do ensino deveria conduzir, logicamente, à intervenção dos poderes públicos em apoio, auxílio dos estudantes.

Subvencionar os estudantes, permitir-lhes aquisições com tarifa preferencial é algo bem diferente do que expropriar os autores.

Dai ponderar MICHĖLE SALCZER-SANCHES, em resposta ao argumento de que possivelmente uma publicação autorizada custe mais 
do que uma reprodução «pirata», que a solução deste problema deve ser encontrada na assunção do custo pelos estabelecimentos de ensino ou por órgão pertinente antes de se desrespeitar os interesses legítimos dos criadores de obras. $\left(^{40}\right)$.

Analisaremos o problema surgido com a reprografia em primeiro lugar sob o aspecto dos subsídios fornecidos pela legislação de alguns países $\left(^{1}\right)$ para em seguida analisar a matéria sob o ângulo do direito convencional $\left({ }^{2}\right)$ :

1 - Com relação à reprodução através de meios mecânicos como a reprografia delineou-se na França uma orientação jurisprudencial no sentido de admitir a reprodução de uma obra para seus alunos e de poder um estudante encomendar cópias de obras para seu uso e ao dos seus colegas de estudos. Porém a orientação doutrinária é no sentido de serem proibidas tais iniciativas.

A verdadeira solução estará no manuseio do direito de autor sem colocar em jogo o princípio do direito exclusivo do autor.

Submeter a utilização das obras com escopo pedagógico a uma licença obrigatória constituiria um rombo nos legítimos direitos dos autores.

Tal opção submeteria à licença legal as obras destinadas ao ensino que raramente são aproveitadas em outros fins.

A orientação correta será permitir o exercício do direito exclusivo através de mecanismos coletivos o que se torna tanto mais realizável se os autores se reunirem em sociedades de defesa de seus direitos que deverão poder negociar, com as autoridades responsáveis da área de estabelecimentos de ensino, contratos em condições vantajosas para todos. $\left.{ }^{41}\right)$.

Passemos à análise da regulamentação do uso da reprografia na Suécia e Alemanha onde as respectivas leis de Direito de Autor são silentes a respeito.

$\mathrm{Na}$ Suécia o problema do uso abusivo da reprografia com fins pedagógicos encontra solução no campo contratual.

Em 1973 um acordo foi firmado entre as autoridades competentes pelos estabelecimentos de ensino e os organismos representativos dos autores e seus titulares de direitos. $\left({ }^{42}\right)$.

Este acordo foi, posteriormente, renovado com algumas modificações e regula o uso da reprografia nos estabelecimentos de ensino públicos e privados de ensino primário e secundário.

(40) MICHELE SALCZER-SANCHEZ - ob. cit., pág. 143.

(41) MICHELE SALCZER-SANCHEZ - ob. cit., pág. 153.

(42) Consultar a Revue Internationale de Droit d'Auteur, volume LXXX, de abril de 1974. 
O sistema adotado permite aos professores de reproduzir obras protegidas sem pedir a autorização de seu autor. $\left({ }^{43}\right)$.

Este sistema, em princípio, apenas se aplica às obras cujos autores estão ligados a uma das entidades signatárias de referido acordo.

Duas hipóteses estão previstas: a) se uma obra é reproduzida em três exemplares ou b) mais do que isso. Na primeira eventualidade, não há direito à remuneração, na segunda situação - mais do que três exemplares, é devida a remuneração.

O número de cópias não deve ultrapassar o que é necessário para atender às necessidades de três turmas de alunos (por volta de cem exemplares).

Diferentes regras visam a colocar a utilização da reprografia numa função de complemento aos meios habituais de ensino.

Os autores associados das entidades encarregadas de administrar seus interesses poderão sempre obstar expressamente a reprodução de uma de suas obras. $\left.{ }^{(44}\right)$.

A remuneração, calculada com base em pesquisa executada em estabelecimentos de ensino, em função do número de cópias reproduzidas, é transferida a uma entidade de nome - BANUS - que a distribuirá entre as várias associações representantes dos autores.

O sistema estabelecido em 1973 não abrange todos os estabelecimentos de ensino e se aplica tão somente às obras dos membros das entidades signatárias.

Na Suécia, em conclusão, nesta matéria coexistem dois sistemas: o das hipóteses abrangidas pelo sistema estabelecido em 1973 e aquelas eventualidades não vinculadas a acordo e que se enquadram na esfera de abrangência da lei do direito de autor. ( ${ }^{45}$ ).

O artigo 11 da Lei de Direito de Autor da Suécia ao regular o uso privado da obra intelctual, conforme sua interpretação usual, admite a possibilidade de reprodução de uma obra em número de vinte exemplares, sem que haja necessidade de autorização e de remunerar o autor.

Quanto se tratar de casos regulados pelo acordo referido as regras constantes do artigo 11 são afastadas e será possível reproduzir uma obra em cem exemplares sendo contudo obrigatória a remuneração em se tratando de reprodução acima de três exemplares.

Passemos a analisar a matéria na República Federal da Alemanha.

A Corte Federal de Justiça, aos 14 de abril de 1978, decidiu um processo a propósito do uso da reprografia para finalidades educacionais.

(43) MICHELE SALCZER-SANCHEZ - ob. cit., pág. 157.

(44) MICHELLE SALCZER-SANCHEZ - ob. cit., págs. 157 e 159.

(45) MICHELE SALCZER-SANCHEZ - ob. cit., págs. 159. 
Fixou o princípio de que tais reproduções estão submetidas à regra do direito exclusivo a não ser que se enquadrem nas eventualidades previstas nos artigos 53 e 54 da Lei de Direito Autoral da Alemanha que prevêem as limitações para uso pessoal ou interno.

Estatui que a reprodução de uma obra protegida por parte de um professor constitui reprodução para uso interno e não reprodução para o uso pessoal de cada aluno.

Só é possível a reprodução a restrito número de exemplares (em número de sete) e não em número de exemplares correspondente ao de alunos. Além de sete exemplars, a reprodução deverá ser mediante remuneração.

A Corte Federal de Justiça ressaltou nesta decisão que quando o legislador desejou tomar em consideração as necessidades do ensino para limitar o exercício do direito de autor o fez de modo expresso, não havendo lugar para criar exceções quando a lei não o prevê. $\left({ }^{46}\right)$.

Precisamos analisar sob o aspecto do Direito Convencional como ficaria a utilização da reprografia com finalidades didáticas.

A Convenção Universal de Direito de Autor permite, com base no artigo IV bis alínea $2^{a}$, que se possa estatuir uma exceção ao direito de autor concernente ao ensino, portanto, neste artigo estará o fundamento para, liberando-se da imperatividade da regra do direito de reprodução, a reprografia ser livremente utilizada para fins pedagógicos, desde que o número das reproduções feitas seja limitado. ${ }^{47}$ ).

Já no que diz respeito à Convenção de Berna o assunto é mais delicado, devendo-se interpretar o artigo 10 alínea $2^{\text {a }}$ no sentido de que sua abrangência não se deverá estender à reprografia. $\mathrm{O}$ artigo 10 , alínea $2^{\mathrm{a}}$ permite a utilização de obras intelectuais no interesse do ensino através de publicações, emissões radiofônicas ou fixações materiais sonoras ou visuais, mas a reprografia não é mencionada no texto e a enumeração sem dúvida alguma é limitativa.

É certo que se desejasse incluir igualmente a reprografia se o teria feito de modo expresso. ${ }^{(48)}$.

Como o artigo 10, alínea $2^{\text {a }}$ é o único na Convenção de Berna em que se pode fundamentar uma exceção no interesse do ensino e como a reprografia não diz respeito ao texto, conclui-se que as disposições da Convenção de Berna não permitem às legislações nacionais prever um limite ao direito de reprodução para a utilização da reprografia com finalidades pedagógicas. $\left({ }^{49}\right)$.

Aplicado o Direito Convencional ao caso brasileiro, levando-se em conta os termos da lei nacional deve-se concluir da necessidade da re-

(46) MICHELL SALCZER-SANCHEZ - ob. cit., págs. 159.

(47) MICHELLE SALCZER-SANCHEZ - ob. cit., págs. 171.

(48) MICHèLE SALCZER-SANCHEZ - ob. cit., págs. 171-173.

(49) MICHELE SALCZER-SANCHEZ - ob. cit., pag. 173. 
gulamentação do uso da reprografia para o que há competência atriDuida ao CNDA - Conselho Nacional de Direito Autoral.

Contudo é aconselhável que soluções sejam procuradas no plano contratual com o que se estará evitando a multiplicação de reproduções ilícitas. E preconizada a negociação de acordos entre as autoridades responsáveis pelos estabelecimentos de ensino e os organismos representativos dos autores e seus titulares. Trata-se de sistema semelhante ao instalado na Suécia. ${ }^{(50)}$.

MICHELE SALCZER-SANCHEZ observa que o mesmo tipo de solução foi proposto a nível de Comunidade Européia.

$\mathrm{E}$ quanto aos videogramas? Os video-discos, video-cassetes ou qualquer suporte material análogo de seqüência de imagens e de sons, utilizados com finalidades didáticas podem enquadrar-se nas limitações ao direito de autor. $\mathrm{O}$ artigo $4^{\circ}$, inciso VIII da Lei $\mathrm{n}^{\circ} 5.988$ fala em videofonograma.

Tal possibilidade se fundamenta, quanto à Convenção Universal de Direito de Autor, no artigo IV bis alínea 2.

Quanto à Convenção de Berna, o artigo 10 alínea $2^{a}$ indica que as obras podem ser utilizadas a título de ilustração de ensino através de fixações materiais sonoras ou visuais categoria em que se incluem os videogramas. ${ }^{51}$ ).

$E ́$ de se ressaltar que as possibilidades oferecidas pelas Convenções Internacionais para a derrogação do Direito de Autor com fundamento em exigências do ensino são relativamente limitadas. ${ }^{52}$ ).

3 - Qual a responsabilidade de um professor universitário quanto à utilização de xerocópias de trabalhos de terceiros para serem distribuídos aos seus alunos como material de apoio?

WILHELM NORDEMANN após esclarecer que toda cópia é em principio uma contrafração ressalta que o professor que fotocopiar uma balada extraída de uma coletânea de poemas e a distribuir entre seus alunos viola o direito de autor o que de acordo com algumas legislações é objeto de sanção. $\left.{ }^{53}\right)$.

Por outro lado, um professor universitário elaborando instrumentos de trabalho partindo de uma obra básica existente obterá uma «criação dependente do original». Portanto o professor que prepara fichas de trabalho objetivando ajudar seus alunos na feitura de seus deveres

(50) MICHALLE SALCZER-SANCHEZ - ob. cit., pág. 173.

(51) MICHèle SALCZER-SANCHEZ - ob. cit., pág. 175.

(52) MICHELE SALCZER-SANCHEZ - ob. cit., pág. 175.

(53) WILHELM NORDEMANN - «Droit d'Auteur et moyens d'enseignement», Revue Internationale de Droit d"Auteur, volume LXV, julho de 1970, pág. 109. Indica o $\$ 106 \mathrm{da}$ Lei da República Federal da Alemanha, o $\$ 46$ da Lei Suiça e o artigo 71 da Lei Francesa de 11 de março de 1957. 
partindo de um manual de matemática ou variando os exercícios do livro com o objetivo de aprofundar os conhecimentos de seus alunos, entrega-se a um trabalho proibido pelo direito de autor. $\left(^{54}\right)$.

4 - No combate à reprodução ilícita através da reprografia é necessário responsabilizar, condenando a indenizações, quem tendo máquinas xerocopiadoras permitir que terceiros delas se utilizem não para os termos da limitação prevista no artigo 49 , inciso $\Pi$ de nossa lei de Direito de Autor, mas, para reproduzirem em muitos exemplares textos de obras protegidas.

Importante precedente jurisprudencial encontramos em acórdão da Corte de Apelação de Paris, $4^{n}$ Câmara, datado de 8 de outubro de 1982 em que a empresa exploradora de máquina fotocopiadora foi condenada a indenização por perdas e danos por ter permitido a reproaução em muitos exemplares de um capítulo de obra protegida.

A ação beneficiou a editora cessionária do direito patrimonial de autor e a precedência da ação fortaleceu a atuação do Comitê National pour la prévention des reproductions illicites que recebeu a indenização simbólica de um franco.

Eis um exemplo a ser seguido entre nós.

MICHELE SALCZER-SANCHEZ conclui seu artigo, que é um resumo de sua tese de doutorado, dizendo que a diversidade de possibilidade mostra como é difícil alcançar um justo equilíbrio entre os interesses dos autores ou de seus titulares e os das pessoas que se utilizam das obras de espirito com fins educacionais.

Ressalta que não existe oposição entre a proteção do Direito de Autor e a satisfação das exigências em matéria de ensino.

Ensino e direito de autor são ambos elementos determinantes do desenvolvimento da sociedade.

O equilíbrio entre a proteção dos direitos de autor e a satisfação das exigências do ensino não deve ser encontrado em detrimento de um ou de outro.

E importante ter isto presente no momento em que o interesse geral é invocado para tentar justificar a utilização das obras intelectuais em detrimento dos direitos de seus autores. $\left({ }^{55}\right)$.

5 - Para finalizar: quanto à proteção de obras orais, é chegado o momento de os professores só aceitarem proferir palestras, conferências desde que devidamente remunerados, pois, trata-se de um labor intelectual que merece uma contraprestação a título de direito de autor, que não se destinando a ser reproduzida, radiodifundida, a receber uma

(54) WILHELM NORDEMANN - ob. cit., página 113.

(55) MICHELEE SALCZER-SANCHEZ - ob. cit., pág. 189. 
fixação material, tem o fato gerador no momento em que a obra oral foi comunicada ao público.

Com isso se evitará a conduta adotada por certas instituições universitárias - na denúncia feita pelo poeta, escritor, jornalista e professor DÉCIO PIGNATARI - de que «só convidam» conferencistas se eles proferirem suas palestras gratuitamente. No entanto os próprios diretórios acadêmicos deveriam ser os primeiros a pagar os seus convidados, ainda que simbolicamente». $\left.{ }^{56}\right)$.

\section{BIBLIOGRAFIA}

Ascensao, JOSA DE OLIVEIRA - «Direito Autoral», Rio, Forense, 1980.

COLOMBeT, CLAUDE - «Proprieté Littéraire et Artistique», Paris, Dalloz, 1966.

DESBOIS, HENRI - «Le Droit d'Auteur en France», Paris, Dalloz, 1966.

DESBOIS, HENRI, FRANCON, ANDRE e KEREVER, ANDRE - «Les conventions internationales du droit d'auteur et des droits voisins», Paris, Dalloz, 1976.

FRANCON, ANDRE - «La propriété littéraire et artistique en Grande Bretagne ot aux Etats Unis», Pariș, Librairie Arthur Rousseau, 1855.

LE TARnec, ALAIN - «Manuel de la Propriété Littéraire et Artistique», Paris, Librairie Dalloz, 1966.

LYON-CAEN, GERARD - «La publication des cours des professeurs d'Universite», em Revue Internationale de Droit d'Auteur, volume LII.

MANSO, EDUARDO VIEIRA - «Direito Autoral», São Paulo, José Bushatsky Editor, 1980.

NORDEMANN, WILHELM - «Droit d’Auteur et moyens d'enseignement», em Revue Internationale de Droit d'Auteur, volume LXV, julho de 1970.

OLAGNIER, PAUL - «Le Droit D'Auteur», I, Paris, Librairie Générale de Droit et de Jurisprudence, 1934.

PADEllaro, GIUSEPPE - «H Diritto d'Autore - la Disciplina Giuridica degli Strumenti Communicazione Sociale», Milano, Casa Editrice Dr. Francesco Vallardi - Società Editrice Libraria, 1972.

PIGNATARI, DÉcIo - «Direitos Autorais jâß, artigo publicado no jornal «Folha de São Paulo», seç̃o Folha Ilustrada, no dia 24 de agosto de 1984.

POIRIER, PIERRE - «Le Droit d'Auteur», Bruxellas, Maison Ferdinand Larcier, sem data.

RINGER, BARBARA - «Judicial developments in United States Copyright», Law (19681969), em Revue Internationale du Droit d'Auteur, volume LXVIII, janeiro de 1971.

SALCZER-SANCHEZ, MICHiLE - «Le Droit d'Auteur et les necessités de l'enseignament», em Revue Internationale du Droit d'Auteur, volume 110.

SATANOVSKY, ISIDRO - «Derecho Intelectual», I, Buenos Aires, Tipografia Editora Argentina, 1954.

STOLFI, NICOLA - «La Proprietà Intelletuale», I, Torino, Unione Tipografico Editrice Torinese, 1915.

VALERIO, ETTORE e ALGARDI, ZARA - «Il Diritto d'Autore», Milano, Dott., A. Giuffrè Editore, 1943.

(56) DÉCIO PIGNATARI - «Direitos Autorals já», artigo publicado no Jornal Folha de São Paulo», seção Folha Ilustrada, no dia 24 de agosto de 1984. 